\title{
Lipoprotein(a) and lipoprotein profile in healthy centenarians: a reappraisal of vascular risk factors
}

\author{
G. BAGGIO, ${ }^{1}$ S. DONAZZAN, D. MONTI, ${ }^{\dagger}$ D. MARI, ${ }^{\dagger}$ S. MARTINI, C. GABELLI, M. DALLA \\ VESTRA, L. PREVIATO, M. GUIDO, ${ }^{\dagger}$ S. PIGOZZO, I. CORTELlA, G. CREPALDI, AND C. \\ FRANCESCHI ${ }^{\dagger, \S, 2}$ \\ Institute of Internal Medicine, University of Padova, Padova, Italy; ${ }^{\dagger}$ Department of Biomedical \\ Sciences, University of Modena, Modena, Italy; ${ }^{\S}$ Italian National Research Centres on Aging, INRCA, \\ Ancona, Italy; and ‘'Institute of Internal Medicine, IRCCS Maggiore Hospital, University of Milano, \\ Milano, Italy
}

ABSTRACT In this study we assessed whether widely accepted risk factors for atherosclerotic vascular diseases such as lipoprotein(a) $[\operatorname{Lp}(\mathbf{a})]$, a cholesterol-rich lipoprotein under strict genetical control, and other lipid parameters change with age. The variations of blood levels and the pathophysiological role of $\operatorname{Lp}(a)$ in old people, and particularly in the oldest old, are unknown. Accordingly, we measured $\operatorname{Lp}(\mathrm{a})$ levels as well as total, LDL, and HDL cholesterol (CT), and triglycerides (TG) in sera from 75 healthy centenarians, 114 randomly selected subjects under 65 years, 73 randomly selected elderly people, and 30 healthy selected elderly people. The results showed that $\mathrm{Lp}(\mathrm{a})$ serum levels did not vary by age group, including centenarians. Remarkably, onequarter of the centenarians had high $\mathrm{Lp}(\mathrm{a})$ serum levels even though they never suffered from atherosclerosisrelated diseases. At variance with young and aged people, centenarians with high $\operatorname{Lp}(a)$ serum levels also had high plasma concentrations of the proinflammatory cytokine IL-6, suggesting that genetic control of the Lp(a) serum level may attenuate with age and that environmental factors such as chronic subclinical inflammatory processes may play a role. We also showed that most centenarians are paradoxically characterized by low HDL-CT and relatively high TG levels, which together are considered to be strong risk factors for coronary heart disease. On the whole, these data support the hypothesis that a continuous and complex reshaping of lipid metabolism occurs in physiological aging, likely contributing to successful aging.-Baggio, G., Donazzan, S., Monti, D., Mari, D., Martini, S., Gabelli, C., Dalla Vestra, M., Previato, L., Guido, M., Pigozzo, S., Cortella, I., Crepaldi, G., Franceschi, C. Lipoprotein(a) and lipoprotein profile in healthy centenarians: a reappraisal of vascular risk factors. $F A S E B J .12,433-437$ (1998)

Key Words: atherosclerosis · lipoproteins · aging · interleukin 6

High LEVELS OF total serum cholesterol (CT), ${ }^{3}$ low density lipoprotein (LDL)-CT, and triglycerides (TG) as well as low levels of high density lipoprotein (HDL)-CT are well-recognized risk factors for cardio- vascular disease $(1,2)$. Recently, lipoprotein(a) $[\operatorname{Lp}(\mathrm{a})]$, a genetically controlled cholesterol-rich lipoprotein whose biological role is still unknown (3), has been suggested by numerous studies as an independent risk factor for premature coronary heart disease, stroke, restenosis of vein grafts after coronary bypass surgery, and peripheral artery disease (4-5); $\operatorname{Lp}(\mathrm{a})$ is present in atherosclerotic plaques and stimulates smooth muscle cell replication (6). Although individual $\operatorname{Lp}(\mathrm{a})$ levels appear to remain remarkably stable, in some pathophysiological states it can behave as an acute-phase protein (7); increased Lp(a) levels have also been found in chronic inflammatory disorders such as rheumatoid arthritis (5). Few and contrasting data have been published about $\operatorname{Lp}(\mathrm{a})$ levels and its atherogenic effect in the elderly (8-10).

The aim of this study was to verify whether the previously mentioned, widely accepted and well-studied lipid risk factors for atherosclerosis and atherosclerosis-related diseases change with age. Accordingly, lipoprotein (a) $[\operatorname{Lp}(\mathrm{a})]$ levels as well as the lipoprotein profile (total, LDL, and HDL cholesterol) were studied in serum samples from 75 centenarians carefully selected for their health status compared with 217 control subjects of different ages, selected either randomly or according to their good health status.

The main and unexpected findings were: 1) $\operatorname{Lp}(\mathrm{a})$ serum levels did not vary in the different ages, including centenarians; 2) $25 \%$ of the centenerians had high levels of $\operatorname{Lp}(\mathrm{a})$; 3) only centenarians (but not young and aged subjects) with high Lp(a) levels had a significantly high serum level of proinflammatory cytokine IL-6; 4) in centenarians, total and

\footnotetext{
${ }^{1}$ Present address: Department of Internal Medicine, University of Sassari, Sassari, Italy.

${ }^{2}$ Correspondence: Department of Biomedical Sciences, Section of General Pathology, University of Modena, Via Campi 287, 41100 Modena, Italy. E-mail: francesc@unimo.it

${ }^{3}$ Abbreviations: CT, cholesterol; LDL, low density lipoprotein; HDL, high density lipoprotein; LP(a), lipoprotein(a); TG, triglycerides; TNF, tumor necrosis factor; IL-6, interleukin 6; ELISA, enzyme-linked immunoassay.
} 
LDL cholesterol levels were similar to those found in young controls, but significantly lower than those found in randomly selected or healthy elderly, whereas HDL cholesterol was lower and triglycerides higher than in young subjects. As far as we know, these are the first data about lipid parameters in centenarians, and they suggest that the biological significance of vascular risk factors may change with advanced age.

\section{METHODOLOGY}

Blood was drawn after $12 \mathrm{~h}$ of fasting from four groups of subjects living in Northern Italy; group 1: 75 healthy centenarians (14 males and 61 females) aged $100-106$ years ( $\bar{x} \pm$ SD: $100.9 \pm 1.4)$; group 2: 114 randomly selected subjects under 65 years (39 males and 75 females) aged 8-64 years ( $\bar{X} \pm$ SD: 35.8 \pm 11.8 ); group 3: 73 randomly selected elderly persons (16 males and 57 females) aged $65-98$ years ( $\bar{x} \pm$ SD: $83.5 \pm 7.6)$; group 4: 30 healthy selected elderly (6 males and 24 females) aged $61-80$ years $(\bar{X} \pm \mathrm{SD}: 71.4 \pm 5.5)$. Group 1 was selected according to clinical, biochemical, and hematological criteria and parameters as previously reported (11); part of this group has been studied for other parameters (12). Group 2 included randomly selected volunteers working in the General Hospital, University of Padua, Italy. These subjects were clinically healthy and attending work (students, medical doctors, nurses, technicians). Group 3 included randomly selected, apparently healthy, old volunteers, about half of them living in institutions for the elderly in Padua city. According to the random selection criteria, no biochemical or hematological analysis was performed in groups 2 and 3 to check their healthy status and no questionnaire for medications was used. Group 4 included old volunteers carefully selected according to the SENIEUR Protocol proposed by Ligthart et al. (13). At the onset, a population of 300 subjects living in Carpi (Modena, Italy), participating in a large study of the health status at a population level, was analyzed for clinical health, several biochemical and hematological parameters, and medications. According to the strict exclusion and inclusion criteria, only 30 subjects were eventually enrolled. All subjects in groups 1-4 were Caucasian and lived in Northern Italy.

$\mathrm{Lp}$ (a) levels were measured in serum by a noncompetitive sandwich enzyme-linked immunoassay (ELISA) method (14); total cholesterol (15), HDL cholesterol (after polyanion precipitation) (16), and triglycerides (17) were measured manually by standard enzymatic methods, LDL cholesterol was calculated by the Friedewald formula. Tumor necrosis factor- $\alpha$ $(\mathrm{TNF}-\alpha)$ and interleukin 6 (IL-6) were measured in plasma with commercially available ELISA (18).

\section{Statistical analysis}

$\mathrm{Lp}$ (a) levels were compared between the groups by the nonparametric Wilcoxon ranked sum test because of the wellknown skewed distribution of the concentration of this lipoprotein in Caucasians; the Student's $t$ test was used to compare lipids, cytokines, and Lp(a) logarithms. The correlation of $\operatorname{Lp}(\mathrm{a})$ levels with age was evaluated with simple linear regression analysis.

\section{RESULTS}

Table 1 shows that no statistically significant age-related differences in $\operatorname{Lp}(\mathrm{a})$ serum concentration were found among the four groups, including centenarians. Indeed, no significant correlations were found between $\operatorname{Lp}(\mathrm{a})$ and age when subjects of all four groups were analyzed together. The same result was obtained when centenarians were excluded from the analysis (data not shown). In centenarians, the serum concentration of $L p(a)$ varied widely among individuals as well as in the three control groups considered here. Moreover, the percent of frequency of subjects with $\mathrm{Lp}$ (a) levels below and above $30 \mathrm{mg} / \mathrm{dl}$, the conventional limit of high-risk levels (3), was similar in the four groups. In particular, $25.3 \%$ of healthy centenarians had Lp(a) levels higher than $30 \mathrm{mg} / \mathrm{dl}$. To identify the possible reason (or reasons) for this unexpected high level of $L p(a)$ in healthy centenarians, we measured the plasma level of proinflammatory cytokines such as IL- 6 and TNF- $\alpha$, which are capable of increasing the plasma level of acute-phase proteins. These measurements were performed in the centenarians (group 1), young subjects (group 2), and old people belonging to group 3 (randomly selected) or 4 (selected for healthy status) who had Lp(a) levels higher than $50 \mathrm{mg} / \mathrm{dl}$ or lower than $10 \mathrm{mg} / \mathrm{dl}$.

Table 2 shows that significantly higher levels of IL6 , but not of TNF- $\alpha$, were present only in centenarians with high $\operatorname{Lp}(\mathrm{a})$ levels. This increase in IL-6 was not present either in young (group 2) or old subjects (groups 3 and 4) with similar high Lp(a) serum concentrations. A marked increase in the IL-6 serum level was found in randomly selected elderly (group 3) compared with healthy selected old people (group 4). This difference in the serum IL-6 level was also evident when all people belonging to these two groups were analyzed $(10.3 \pm 0.7 \mathrm{pg} / \mathrm{ml}$ vs. $1.8 \pm 0.3$ $\mathrm{pg} / \mathrm{ml}$ in 65 subjects of group 3 and 29 subjects of group 4, respectively, $P<0.0001)$.

Serum lipid and lipoprotein levels were measured in healthy centenarians as well as in the other three groups considered in this study (Table 3). Healthy centenarians showed: 1) total and LDL cholesterol levels similar to young subjects, but significantly lower than in randomly or healthy selected elderly; 2) HDL cholesterol values similar to randomly selected elderly, but significantly lower than in young subjects; and 3) triglyceride levels significantly higher than those found in young people, but similar to elderly subjects.

\section{DISCUSSION}

Several studies indicate that altered serum lipid and lipoprotein levels can be considered important risk factors for atherosclerotic vascular diseases $(1,2)$. In particular, high levels of LDL-CT and low levels of HDL-CT have been described in patients who suffer coronary heart disease (19). More recently, high levels of $\operatorname{Lp}(\mathrm{a})$ have been considered an independent 


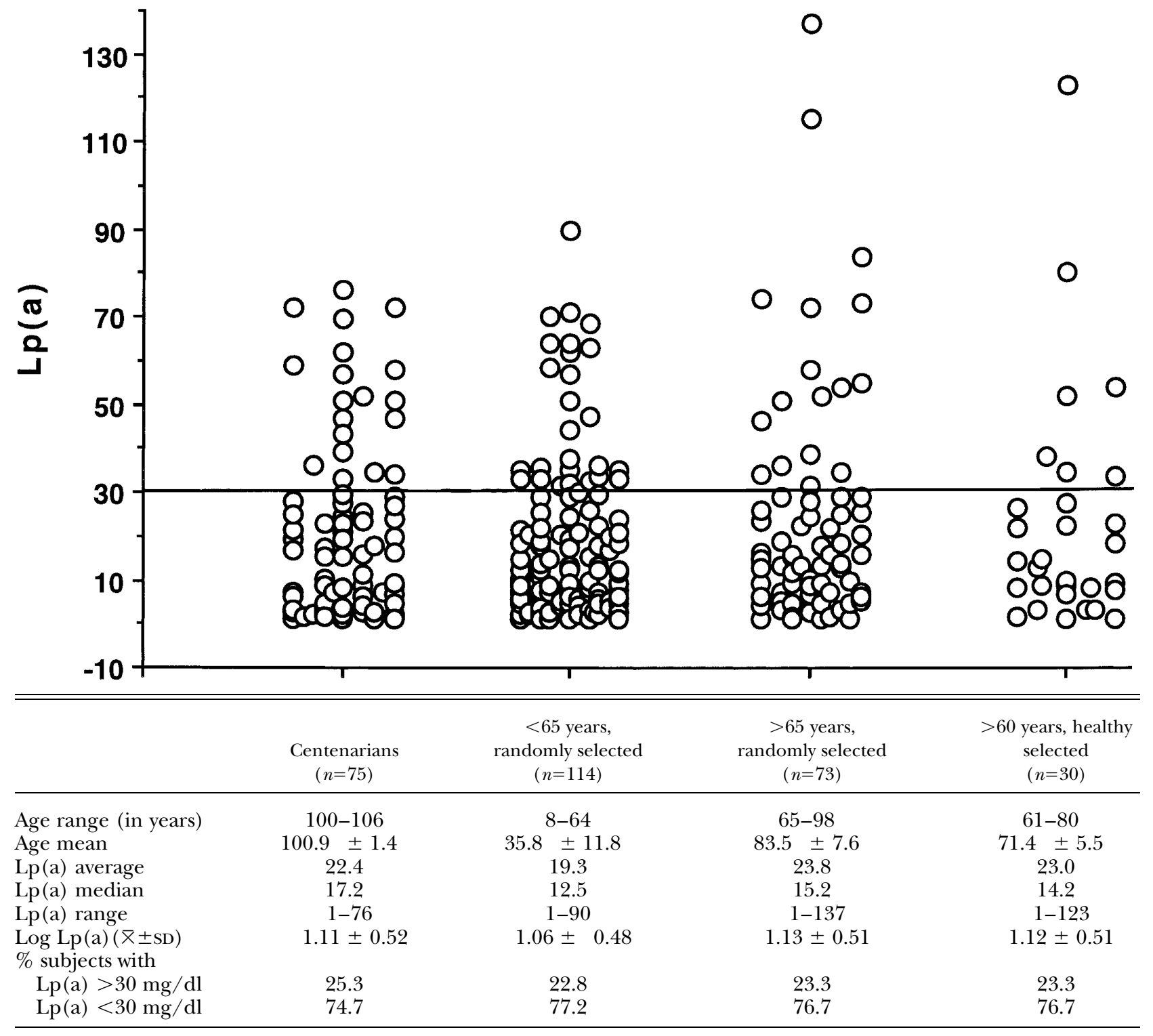

risk factor for atherosclerotic vascular diseases (4-5). The serum level of this lipoprotein is apparently under strict genetic control and shows a poor response to hypolipidemic diet and/or drugs $(3,20)$. Thus, it could be expected that healthy elderly, and particularly healthy centenarians (people who escaped major age-related diseases, including vascular accidents such as stroke and myocardial infarction), had low levels of $\operatorname{Lp}(\mathrm{a})$ as well as a favorable lipoprotein pattern. Moreover, as it is known that all atherosclerotic vascular diseases increase with age (21), it could be expected that serum levels of $\operatorname{Lp}(\mathrm{a})$ also change with age. These predictions were only partially fulfilled.

First, the median and mean $\log$ of serum $\operatorname{Lp}(\mathrm{a})$ levels did not change with age (Table 1). Second, a quarter of healthy centenarians had $\operatorname{Lp}(\mathrm{a})$ levels considered to put them at risk for atherosclerosis and related complications. This paradoxical finding ap- parently challenges the tenet that high levels of $\mathrm{Lp}(\mathrm{a})$ are an independent risk factor for the above-mentioned diseases. To fully evaluate these data, we should know whether this portion of centenarians $(25 \%)$ were characterized for their entire life by such high levels of $\operatorname{Lp}(\mathrm{a})$. This question remains unanswered until longitudinal studies are performed. This finding in healthy centenarians who suffered no vascular disease in their long life suggests either that $\mathrm{Lp}(\mathrm{a})$ is not a risk factor in the oldest-old or that it is counteracted by unknown protective factors whose identification would be of great interest. Alternatively, it could be speculated that $\operatorname{Lp}(\mathrm{a})$ may have a paradoxical protective effect that emerges only later in life in selected people such as healthy centenarians. Such phenomena are not completely unexpected according to one of the most accepted theories of aging: pleiotropic antagonism (22). 


\begin{tabular}{|c|c|c|c|c|}
\hline & $\mathrm{Lp}(\mathrm{a})(\mathrm{mg} / \mathrm{dl})$ & $\mathrm{TNF}-\alpha(\mathrm{pg} / \mathrm{ml})$ & IL-6 $(\mathrm{pg} / \mathrm{ml})$ & Age (years) \\
\hline \multicolumn{5}{|l|}{ Centenarians } \\
\hline $\operatorname{High} \operatorname{Lp}(a)(n=8)$ & $65.0 \pm 3.09$ & $2.68 \pm 0.57$ & $17.66 \pm 8.48^{*}$ & $102 \pm 0.93$ \\
\hline Low $\operatorname{Lp}(a)(n=12)$ & $4.33 \pm 0.81$ & $2.53 \pm 0.53$ & $3.11 \pm 0.60$ & $101 \pm 0.51$ \\
\hline \multicolumn{5}{|l|}{ Young controls } \\
\hline High Lp(a) $(n=6)$ & $77.8 \pm 14.1$ & $1.87 \pm 0.35$ & $3.87 \pm 0.40$ & $33.0 \pm 5.02$ \\
\hline Low $\operatorname{Lp}(a)(n=6)$ & $2.75 \pm 0.53$ & $2.40 \pm 1.29$ & $3.10 \pm 0.28$ & $35.0 \pm 2.53$ \\
\hline \multicolumn{5}{|c|}{$>65$ years, randomly selected } \\
\hline $\operatorname{High} \operatorname{Lp}(a)(n=9)$ & $77.4 \pm 10.01$ & n.d. & $9.75 \pm 2.01$ & $84.3 \pm 3.00$ \\
\hline Low $\operatorname{Lp}(\mathrm{a})(\mathrm{n}=26)$ & $4.99 \pm 0.58$ & n.d. & $9.75 \pm 1.23$ & $84.6 \pm 1.56$ \\
\hline \multicolumn{5}{|c|}{$>65$ years, healthy selected } \\
\hline $\operatorname{High} \operatorname{Lp}(a)(n=4)$ & $77.2 \pm 16.53$ & n.d. & $3.43 \pm 2.06$ & $71.0 \pm 3.03$ \\
\hline Low $\operatorname{Lp}(a)(n=12)$ & $6.13 \pm 0.97$ & n.d. & $1.25 \pm 0.11$ & $71.8 \pm 1.25$ \\
\hline
\end{tabular}

${ }^{a} P<0.05$ vs. centenarians with low $\operatorname{Lp}(\mathrm{a}) ;$ n.d. $=$ not determinated.

Another tenet challenged by our data is that $\operatorname{Lp}(\mathrm{a})$ is mostly or strictly under genetic control and that environmental influences play a negligible role. On the contrary, the high level of IL- 6 only in centenarians with high $\operatorname{Lp}(\mathrm{a})$ serum levels, but not in young and aged subjects, suggests that genetic control of the serum level of $\operatorname{Lp}(\mathrm{a})$ may attenuate with advanced age where environmental factors, such as chronic subclinical inflammatory process, may be involved $(5,23)$.

The increased number of activated $\mathrm{T}$ cells described in the peripheral blood of centenarians fits this interpretation (11). Moreover, an increase in the production of proinflammatory cytokines, particularly IL-6, occurs with age $(18,24)$, and includes centenarians (unpublished data). Accordingly, Lp(a) could behave as an acute-phase protein, such as fibrinogen, which also showed a paradoxical increase in healthy centenarians (25).

Another interesting result from this study is the marked difference concerning IL-6 serum levels in randomly selected vs. strictly selected healthy elderly. Indeed, high levels of IL-6 were found in the randomly selected elderly persons, a group that likely includes the most subjects with subclinical diseases. Low serum levels of IL-6 appear to be a reliable marker of healthy status; conversely, high levels of this cytokine can be considered a potent risk factor in the elderly. This finding is in accord with recent data suggesting that high levels of IL-6 are predictors of morbidity in longitudinal studies of cohorts of elderly people (26). From this point of view, the occurrence of healthy centenarians with high levels of IL-6 is another paradox to be added to the increasing list of risk factors that apparently change their biological significance in centenarians $(12,25)$.

This finding regarding the serum level of $L p(a)$ in centenarians occurs concomitantly with other interesting changes in serum levels of other major lipids and lipoproteins. Indeed, most centenarians were also characterized by low HDL cholesterol and relatively high triglycerides, two parameters together considered a very strong risk factor for coronary heart disease. On the whole, the levels of plasma lipids and lipoproteins in centenarians apparently are a mixture of characteristics considered either favorable (low total and LDL CT) or unfavorable (low HDLCT and high TG) for atherosclerosis in young people.

Our data seem to suggest that the physiological and pathological roles of $\mathrm{Lp}(\mathrm{a})$ likely change with age despite the relatively stable serum levels of this lipoprotein throughout the entire human life span. These data also support the hypothesis that a continuous reshaping in lipid physiology occurs with age and is likely a critical factor for survival and successful aging.

TABLE 3. Lipid and lipoprotein levels $(\mathrm{mg} / \mathrm{dl} ; \overline{\mathrm{X}} \pm S \mathrm{SD})$ in centenarians and controls

\begin{tabular}{lcccc}
\hline \hline & $\begin{array}{c}<65 \text { years, } \\
\text { Centenarians } \\
(n=75)\end{array}$ & $\begin{array}{c}>65 \text { years, } \\
\text { randomly selected } \\
(n=114)\end{array}$ & $\begin{array}{c}\text { randomly selected } \\
(n=73)\end{array}$ & $\begin{array}{c}>60 \text { years, healthy } \\
\text { selected }(n=30)\end{array}$ \\
\hline CT & $189.8 \pm 34.9^{\circ *}$ & $195.9 \pm 29.8$ & $228.1 \pm 45.1$ & $223.3 \pm 33.2$ \\
LDL-CT & $115.1 \pm 27.8^{\circ}$ & $117.0 \pm 26.3$ & $145.5 \pm 37.1$ & n.d. \\
HDL-CT & $49.2 \pm 12.9^{\circ *}$ & $62.2 \pm 14.8$ & $54.8 \pm 16.5$ & n.d. \\
TG & $125.3 \pm 65.0^{*}$ & $86.1 \pm 32.4$ & $139.0 \pm 59.6$ & $112.8 \pm 48.6$ \\
\hline
\end{tabular}

${ }^{\circ} P<0.001$ vs. $>65$ yrs randomly selected. ${ }^{\circ} P<0.05$ vs. $>65$ yrs randomly selected. ${ }^{\#} P<0.001$ vs. $>60$ yrs healthy selected. $* P<0.001$ vs. $<65$ yrs randomly selected. 
A major consequence of this reshaping is that changes in the serum level of protein, lipids, and lipoproteins that are considered risk factors for atherosclerotic vascular diseases in young people may lose their biological significance and assume a different, unknown role with advanced age. Such a reshaping can have far-reaching consequences for laboratory standard values and, when possible, in therapeutic intervention for the elderly. The results presented here are in line with our general hypothesis that a continuous remodeling develops with time as a result of the continuous adaptation to changes occurring in the body with age in response to internal and external damaging agents (27).

This paper has been supported by grants from the Italian National Research Council, Targeted Project "AGING", (CNR; Progetto Finalizzato Invecchiamento), and the Padova Center for Aging Study of the National Research Council (CNR) Council for the Study of Aging.

\section{REFERENGES}

1. Martin, M. J., Hulley, S. B., Browner, W. S., Kuller, L. H., and Wentworth, D. (1986) Serum cholesterol, blood pressure and mortality: implication from a cohort of 361.662 men. Lancet $\mathbf{i}$, 933-936

2. Assmann, G., and Schulte, H. (1992) Relation of high density lipoprotein cholesterol and triglycerides to incidence of atherosclerotic coronary artery disease: the PROCAM experience. Am. J. Cardiol. 70, 733-737

3. Utermann, G. (1989) The mysteries of lipoprotein(a). Science 246, 904-910

4. Maher, V., and Brown, B. G. (1995) Lipoprotein(a) and coronary heart disease. Curr. Opin. Lipidol. 6, 229-235

5. Dahlen, G. (1994) Lp(a) lipoprotein in cardiovascular disease. Atherosclerosis 108, 111-126

6. Liu, A. C., and Lawn, R. M. (1994) Vascular interactions of lipoprotein(a). Curr. Opin. Lipidol. 5, 269-273

7. Maeda, S., Abe, A., Seishima, M., Makino, K., Noma, A., and Kawade, M. (1989) Transient changes of serum Lipoprotein(a) as an acute phase protein. Atherosclerosis 78, 145-150

8. Jenner, J. L., Ordovas, J. M., Lamon-Fava, S., Schaefer, M. M., Wilson, P. W., Castelli, W. P., and Schaefer E. J. (1993) Effects of age, sex, and menopausal status on plasma Lipoprotein (a) levels. The Framingham offspring study. Circulation 87, 11351141

9. Simons, L., Friedlander, Y., Simons, J., and McCallum, J. (1993) Lipoprotein(a) is not associated with coronary heart disease in the elderly: cross-sectional data from the Dubbo study. Atherosclerosis 799, 87-95
10. Miyashita, Y., Morimoto, S. Fukuo, K., Imanaka, S., Koh, E., Tamatani, M., and Hogihara, T. (1992) Participation of decreased serum cholesterol ester transfer protein, independent of increased serum lipoprotein (a), in angina pectoris in normolipemic elderly subjects. Gerontology. 38, 258-267

11. Sansoni, P., Cossarizza, A., Brianti, V., Fagnoni, F., Snelli, G., Monti, D., Marcato, A., Passeri, G., Ortolani, C., Forti, E., Fagiolo, U., Passeri, M., and Franceschi, C. (1993) Lymphocytes subsets and natural killer cell activity in healthy old people and centenarians. Blood 82, 2767-2773

12. Mari, D., Mannucci, P. M., Duca, F., Bertolini, S., and Franceschi, C. (1996) Mutant factor V (Arg506GIn) in healthy centenarians. Lancet 347, 1044

13. Ligthart, G. J., Corberand, J. X., Fournier, G., Galanaud, P., Hijmans, W., Kennes, B., Muller-Hermelink, H. K., and Steinmann, G. G. (1984) Admission criteria for immunogerontological studies in man: the senieur protocol. Mech. Ageing Dev. 28, 47-55

14. Helmhold, M., Bigge, J., Muche, R., Mainoo, J., Thiery, J., Seidel, D., and Armstrong, V. W. (1991) Contribution of the Apo(a) phenotype to plasma $\mathrm{Lp}$ (a) concentration shows considerable ethnic variation. J. Lipid Res. 32, 1919-1928

15. Allain, C. C., Poon, L. S., and Chan, C. S. G. (1974) Enzymatic determination of total serum cholesterol. Clin. Chem. 20, 470475

16. Warnick, G. R., Benderson, J., and Albers, J. (1982) Dextran sulphate $\mathrm{Mg}^{2+}$ precipitation procedure for quantitation of high density lipoprotein cholesterol. Clin. Chem. 28, 1379-1388

17. Fossati, P., and Principe, L. (1982) Serum triglycerides determined colorimetrically with an enzyme that produces hydrogen peroxides. Clin. Chem. 28, 2077-2080

18. Fagiolo, U., Cossarizza, A., Scala, E., Fanales-Belasio, E., Ortolani, C., Cozzi, E., Monti, D., Franceschi, C., and Paganelli R. (1993) Increased cytokine production in mononuclear cells of healthy elderly people. Eur. J. Immunol. 23, 2375-2378

19. Castelli, W. P., Garrison, R. J., and Wilson, P. (1986) Incidence of coronary heart disease and lipoprotein cholesterol levels. The Framingham Study. J. Am. Med. Assoc. 256, 2835-2850

20. Berglund, L. (1995) Diet and drug theraphy for lipoprotein(a). Curr. Opin. Lipidol. 6, 48-56

21. Corti, M. C., Guralnik, J. M., and Bilato C. (1996) Coronary heart disease risk factors in older persons. Aging Clin. Exp. Res. 8, 7589

22. Rose, M. R. (1991) The Evolutionary Biology of Aging, Oxford University Press, Oxford

23. Rantapaa-Dalqvist, S., Wallberg-Jonsson, S., and Dahlen, G. (1991) Lipoprotein(a), lipids and lipoproteins in patients with rheumatoid arthritis. Ann. Rheum. Dis. 50, 366-374

24. Hersheler, W. B. (1993) Interleukin-6: a cytokine for gerontologists. J. Am. Geriatr. Soc. 41, 176-181

25. Mari, D., Mannucci, P. M., Coppola, R., Bottasso, B., Bauer, K. A., and Rosemberg R. D. (1995) Hypercoagulability in Centenarians: the paradox of successful aging. Blood 85, 3144-3149

26. Cohen, H. J., Pieper, C. F., Harris, T., Rao, K. M., and Currie, M. S. (1997) The association of plasma IL-6 levels with functional disability in community-dwelling elderly. J. Gerontol. 52, M201M208

27. Franceschi, C., Monti, D., Sansoni, P., and Cossarizza, A. (1995) The immunology of exceptional individuals: the lesson of centenarians. Immunol. Today 16, 12-16

Received for publication October 31, 1997. Accepted for publication November 25, 1997. 